\title{
RECENT STRATEGIES FOR IMPROVING SOLUBILITY AND ORAL BIOAVAILABILITY OF PIPERINE
}

\author{
HULWA SALSABILA ${ }^{1}$, LILI FITRIANI ${ }^{1}$, ERIZAL ZAINI ${ }^{*}$
}

\author{
1Department of Pharmaceutics, Faculty of Pharmacy, Universitas Andalas, Padang, Indonesia, 25163
}

*Email: erizal@phar.unand.ac.id

Received: 25 Mar 2021, Revised and Accepted: 06 May 2021

\begin{abstract}
Piperine, the main bioactive compound found in black pepper (Piper nigrum L.), has long been used in Ayurveda and traditional Chinese medicine (TCM). This compound has remarkable potential pharmacological properties, including being anti-inflammatory, antimicrobial, anticancer, anticonvulsant, antidepressant, neuroprotective, and hepatoprotective. Recent studies have reported piperine activity as an antiviral against SARSCoV-2, which caused COVID-19. Nevertheless, the clinical use of piperine is still limited, due to its poor water solubility and bioavailability; therefore, various approaches have been developed in order to solve these limitations. This review summarises recent studies (i.e. uploaded to electronic databases in the last $10 \mathrm{y}$ ) regarding strategies that have been investigated to improve piperine's solubility and pharmacokinetic properties, using 'piperine', 'solubility', 'bioavailability', and 'formulation' as keywords. Articles that have focused on piperine as the main compound were selected and sorted based on their modification and formulation types. Studies reported various approaches: from derivatives and analogue synthesis, crystal engineering, complexation, particle size reduction (micro-and nanonisation), and lipid-and polymer-based drug delivery systems, to inorganic and hybrid nanoparticles. This review also highlights limitations and challenges for these approaches and encourages further studies to optimise piperine's potential benefits.
\end{abstract}

Keywords: Piperine, Solubility, Bioavailability, Formulations, Drug delivery systems

(C) 2021 The Authors. Published by Innovare Academic Sciences Pvt Ltd. This is an open access article under the CC BY license (https://creativecommons.org/licenses/by/4.0/] DOI: https://dx.doi.org/10.22159/ijap.2021v13i4.41596. Journal homepage: https://innovareacademics.in/journals/index.php/ijap

\section{INTRODUCTION}

Piperine is the major bioactive component found in black pepper (Piper nigrum L.) that gives pepper its distinctive pungent flavor [1] Aside from being used as a spice for culinary purposes in many countries, pepper also has a long history of use as traditional medicine. In Ayurvedic medicine, pepper is a component of 'trikatu' (black pepper, long pepper and ginger in equal proportions), which is the basis for 210 of the 370 formulations used in the Handbook of Domestic Medicine and Common Ayurvedic Remedies [2]. Pepper is also used traditionally to treat fever and various gastrointestinal conditions, as well as neurological disorders and pulmonary disorders such as asthma and chronic bronchitis [2]. Other traditional medicine systems, such as TCM, use black pepper to treat various pains (e. g. muscle aches and headaches), rheumatism, and infections such as strep throat and influenza, as well as to improve blood circulation [3]. Based on its utilisation in traditional medicine, extensive in vitro and in vivo studies regarding the bioactivity of piperine have been conducted and reported: a very wide range of bioactivity, including anti-inflammatory, antimicrobial, anticancer, anti-diabetic, anti-obesity, antihyperlipidemia, anticonvulsant, antidepressant, antiepileptic, neuroprotective, and hepatoprotective $[1,2,4,5]$. Recent studies on piperine by in silico method showed that piperine has antiviral activity against the SARS-CoV-2 virus that caused COVID-19, through inhibition of virus replication and the ACE-2 receptor $[6,7]$.

Despite its broad and potential bioactivity, the clinical use of piperine is still limited, due to physicochemical properties that pose challenges for its development as a medicinal compound. Piperine has a low water solubility of $0.04 \mathrm{mg} / \mathrm{ml}$ which falls into the practically insoluble category based on the U. S. Pharmacopoeia, but is highly lipophilic with a $\log \mathrm{P}$ value of 2.25 [3]. This results in dissolution as the rate-limiting step in piperine's absorption process in the gastrointestinal tract, causing an erratic oral bioavailability and low in vivo pharmacological effectiveness. Piperine photostability is also a problem because it is susceptible to isomerisation caused by UV rays, which also affect its concentration in preparation during manufacture, storage, and administration [810]. Therefore, in order to optimise piperine's therapeutic benefits and clinical applications, the problems with its physicochemical properties need to be solved by developing appropriate and effective methodological approaches, which could increase its bioavailability and pharmacological effects tremendously. This article reviews the latest developments and studies regarding strategies to improve solubility and bioavailability of piperine that have been reported in the last $10 \mathrm{y}$.

\section{Derivatives and analogue synthesis}

Synthetic approaches have been carried out to produce piperine derivatives by stereoselective fluorination, which replaces the conjugated hydrocarbon chains in piperine with vicinal difluoroalkane groups, resulting in incremental photostability after exposure to sunlight for $2.5 \mathrm{~h}$ [11]. This result, acrossed from intact piperine undergoing extensive decomposition in its geometric isomers, was indicated by a large number of new signals in the alkenyl region in the ${ }^{1} \mathrm{H}$ NMR spectroscopy analysis [11]. Moreover, this analogue also appears to preserve or potentiate piperine's acetylcholinesterase inhibitor activity, while simultaneously enhancing aqueous solubility [11]

Crystal engineering: polymorphism, salt, and cocrystals formation

Mostly, drugs in crystalline form have higher lattice energy, which correlates to their poor solubility in water. Utilising crystal polymorphism could lead to finding another crystalline form with better solubility. Crystal polymorphs have the same chemical composition in each crystal with different internal structures, thus improving physicochemical properties due to changes in the lattice structure and/or molecular conformation [12]. Piperine crystalline polymorph discovery has been reported and revealed in two novel polymorphs with enhanced solubility up to 1.6-fold by polymerinduced heteronucleation (PIHn) method [13]. Thermodynamic studies showed that the formed polymorph is a monotropic metastable crystalline form, which accounted for its increased solubility. Salt formation of piperine with saccharin has been reported, resulting in dissolution rate improvement [14]. The difference between $\mathrm{pKa}$ value of piperine (weak base $\mathrm{pKa}=13.2$ ) and saccharin (weak acid pKa $=1.6$ ) allows the formation of salttype multicomponent crystals $[15,16]$. In another study, piperine cocrystal formation with succinic acid as coformer has been reported, with solubility and dissolution four and two times higher than that of intact piperine, respectively [17]. In general, improved 
solubility in salt and/or cocrystal were due to decreased crystallinity and intramolecular interactions in the crystal lattice, resulting in a decrease in crystal lattice energy and its enthalpy [14, 17]. Particularly in the formation of piperine-succinic acid cocrystal, a channel motive structure is thought to be the main mechanism underlying the increase in piperine's solubility and dissolution [17].

\section{Self-emulsifying drug delivery system (SEDDS) and micro/ nanoemulsions}

Colloid delivery systems based on microemulsions or nanoemulsions are increasingly being used to encapsulate, protect, and deliver hydrophobic bioactive components. In particular, the self-emulsifying drug delivery system (SEDDS) has received considerable attention for formulating piperine in an orally administered emulsion because of its high physical stability and easy preparation $[18,19]$. Piperine formulations in micro/nanoemulsion and SMEDDS/SNEDDS were successful in increasing dissolution rate and modulate pharmacokinetics, resulting in better bioavailability and bioactivity [18-20]. Modification of liquid-SMEDDS to solidSMEDDS has also been carried out and provides a significant increment in drug release and permeation profiles-greater than liquid-SMEDDS and pure piperine [19]. Microemulsions (ME) piperine formulation, as a targeted delivery to the brain for treating Alzheimer's disease, exhibited sustained-release behaviour with superior efficacy and brain delivery compared to pure piperine [20]. In the study, tween 80 and cremophor RH40 were chosen as bioactive surfactant mixtures due to their ability to protect piperine from pre-systemic metabolism by inhibiting liver microsomal enzymes [21]. Furthermore, tween 80 has a role as a brain-targeting agent due to its ability to adsorb Apo-E from circulation and cross the blood-brain barrier by brain LDL-mediated endocytosis [22]. Nanotoxicology studies showed ME's safety in brain cells, but potential nephrotoxicity was observed and chronic use should be considered with caution [20].

\section{Lipid-based drug delivery systems}

Lipid-based drug delivery systems (LBDDS) have become foremost in recent years due to their ability to encapsulate or dissolve hydrophobic drugs in lipid, resulting in increased absorption and bioavailability. Various types of piperine formulation in lipid-based drug delivery systems have been demonstrated recently, including solid lipid nanoparticles, nanostructured lipid carriers, complexation with phospholipid, liposomes, and cubosomes.

Solid lipid nanoparticles (SLN) are the first generation of lipid-based nanocarriers which resemble emulsion structurally. The difference lies in the liquid lipids from the emulsion being replaced with solid lipids, stabilized by surfactants on the surface $[23,24]$. Administration of piperine in the SLN formulation with polysorbate 80 coating $(2 \mathrm{mg} / \mathrm{kg})$ resulted in longer piperine exposure with higher levels (AUC) in the brain and demonstrated increased effectiveness on ibotenic acid-induced Alzheimer's Wistar rats, superior to Donepezil ( $5 \mathrm{mg} / \mathrm{kg}$ ) as standard [25]. However, SLN has several drawbacks due to its highly ordered crystalline structure of solid lipids and drug expulsion during storage, including polymorphic transitions, unpredictable gelation tendencies, and low encapsulation efficiency. Therefore, the second generation of lipid carriers, nanostructured lipid carriers (NLC), was developed through the inclusion of liquid lipid in the solid lipid phase [26]. Piperine formulation with Compritol® 888 ATO as solid lipid phase and squalene as liquid lipid in NLC was recently reported as resulting in a piperine amorphous formation in NLC matrix that encapsulated efficiently $(91.8 \% \mathrm{EE})$ with sustained-release profile (38\% within $12 \mathrm{~h}$ ) [27].

Phospholipid-drug complexation formed by hydrogen or covalent bonding can improve bioavailability by utilising the similar absorption mechanism of nutritional triglycerides and essential phospholipids through enterocytes' passive diffusion, then being transported by chylomicron into systemic circulation via the intestinal lymphatic system, bypassing the first-pass metabolism $[28,29]$. Complexation of piperine with hydrogenated soya bean phosphatidylcholine (HSPC) as a phospholipid has been found to significantly increase its solubility $(0.04 \mathrm{mg} / \mathrm{ml}$ to $1.18 \mathrm{mg} / \mathrm{ml})$, dissolution efficiency and bioavailability, along with its sustained release behaviour on account of complexation by hydrogen bonding between the amide group $\left(-\mathrm{NH}_{2}\right)$ of piperine and $-\mathrm{P}=0$ of HSPC [30]. These results were supported by PXRD, which showed piperinephospholipid complexation by reduced piperine crystallinity and amorphous state formation [30]. The physical mixture did not show any significant change in pharmacokinetic parameters compared to pure piperine, indicating that complexation was a determinant in pharmacokinetic improvement [30].

Liposomes are closed spherical vesicles consisting of one or more phospholipid bilayers with an entrapped aqueous phase. Liposomes could enhance bioavailability due to their good adherence to the biomembrane which increases cellular contact and diffusion across epithelial and mucosal layers [31,32]. Liposomes also provide flexibility for a customise drug release rate that can be adjusted in accordance with the application's purpose, although thermodynamic instability is still a problem [33]. Two recent studies on liposomal piperine using soy phosphatidylcholine and dipalmitoylphosphatidylcholine (DPPC) as matrices have increased its stability at temperature exposure, indicated by a significantly reduced degradation rate along with a delayed-sustained release profile and good encapsulation efficiency, but long-term shelf stability remains a challenge $[34,35]$.

Cubosomes are one of the latest developments in lipid-based nanocarriers. They are thermodynamically-stable nanostructures of bicontinuous cubic phase liquid crystal, formed by certain amphiphilic lipids with self-assembly ability [36]. Their self-assembling nature leads to a relatively lower need for stabiliser/surfactant concentration compared to other nanocarriers, which is an advantage in oral delivery. Moreover, cubosomes are superior to other lipid delivery systems due to their high stability and high surface area, and thus higher loading capacity [37]. Formulation of piperine in cubosomes increased the ability to deliver piperine to the brain via the oral route for Alzheimer's therapy, due to the combined effect of Tween 80 stabilizer (brain-targeting surfactant) and poloxamer 407 (cubosomes stabilizer) with sustained-release and augmented bioactivities (cognitive function, oxidative stress parameters and AChE activity restoration to a normal level) [38]. Furthermore, nanotoxicological studies demonstrated the safety of this formulation for the liver, kidneys, and brain [38].

\section{Inclusion complexes}

Inclusion complexes are complex systems between hosts (complexing agents), which have hydrophobic (inside of cavity) and hydrophilic (outside of cavity) properties that encloses a guest molecule (mostly a hydrophobic drug). This cavity increases the solubility of hydrophobic drugs through van der Waals interactions, hydrophobic interactions, and/or hydrogen bond $[39,40]$. There are at least two types of inclusion complex formulations: binary inclusion complexes (BIC) which consist of piperine and a complexing agent, and ternary inclusion complexes (TIC), a supramolecular stable system which consists of a little amount of auxiliary component in a form of hydrophilic polymer in addition to BIC, and has proven its superiority in enhancing drug solubility compared to BIC [41-43]. Piperine BIC formation using cyclodextrins (CD) along with derivatives such as ethylenediamine$\beta-C D(E N-\beta-C D)$ and hydroxypropyl- $\beta-C D$ (HP- $\beta-C D)$ have succeeded in increasing solubility, dissolution rate, intestinal absorption, bioavailability, bioaccessibility, and bioactivity [42-48]. Particle size did not have a role in solubility improvement. Instead, these improvements were due to the molecular solid-state interaction between various moiety in piperine and $C D$, as confirmed by Raman spectra, together with a decrease in crystal lattice energy and amorphous formation as shown on PXRD analysis $[46,47]$. Studies using synthetic derivatives cyclodextrins (HP- $\beta$-CD) showed a higher stability constant (Ks) and complexation efficiency (CE) than PIP/ $\beta$ $C D$. This indicates that piperine has a greater affinity with HP- $\beta-C D$, possibly due to its better solubility and complexing properties compared to PIP- $\beta$-CD [43]. These modified cyclodextrins even have lower toxicity compared to other solubilizing agents such as surfactants and cosolvents, meaning complexation techniques have significant advantages over other delivery systems [49]. 
TIC formation by adding hydrophilic polymers increased Ks and CE of piperine BIC with $\beta$-CD and HP- $\beta$-CD. This would allow smaller amount usage of $C D$, and hence could prevent a high final dose [4143]. One study showed the addition of $d$ - $\alpha$-tocopheryl polyethylene glycol succinate (TPGS) in piperine CD-based BIC gave synergistic action between surfactant effect of TPGS and complexation solubilisation of $\mathrm{CD}$, resulting in significant enhancement of piperine's solubility, dissolution, and bioactivity [42]. Furthermore, the same study demonstrated how the microwave irradiation method produced a greater increase in solubility and dissolution compared to samples prepared by the solvent evaporation method, as uniform heat production in the sample at the same rate provides better contact between molecules [42].

Other complexing agents that have been used in inclusion complexation with piperine were kappa-carrageenan and cucurbiturils $[50,51]$. Kappa-carrageenan-piperine complexation (equivalent to 100 $\mathrm{mg} / \mathrm{kg}$ of piperine) showed enhancement in $\mathrm{C}_{\max }$ and antiinflammatory activity, even slightly higher than acetosal $(45 \mathrm{mg} / \mathrm{kg})$, compared to pure piperine [51]. In addition, cucurbiturils-piperine complexation showed a stable inclusion complex with low reactivity under the calculation of global reactivity descriptors, which could prevent piperine isomerization to chavicine [50].

\section{Solid dispersions}

Solid dispersions are eutectic mixtures or solid solutions between drugs and water-soluble carriers that increase drug solubility through amorphous formation or supersaturation, due to molecular dispersions and/or polymer solubilisation effects [31, 52]. Polymer matrices have a role in inhibiting the nucleation and recrystallisation that tend to happen due to the high energy of amorphous state and the thermodynamics or kinetics of supersaturated solution [31,53]. Solid dispersions techniques have been demonstrated to successfully increase piperine's solubility and bioavailability by amorphous state formation which, stabilised by hydrogen bonding with Soluplus ${ }^{\circledR}$, could hinder recrystallisation [53-56]. Eudragit L100-55 and hydroxypropylmethylcellulose acetate succinate (HPMCAS) showed acid-base interaction between their carboxyl groups and piperine, which enhanced piperine dissolution and maintained supersaturated solution [53]. Eudragit L100-55 gave the highest solubility enhancement while HPMCAS-HF gave the highest crystallisation inhibition, as its strong hydrophobic interactions with piperine and large steric hindrance obstructed diffusion-controlled crystal growth [53]. Solid dispersions have also been applied in the manufacture of fast-disintegrating tablets (FDT) from sustained-release piperine pellets (Pip-SR) consisting of piperine in solid dispersions (Pip-SD) and HPMC [56]. Pip-SR was able to maintain its structural integrity during compression, and when uniformly distributed in FDT, resulted in a similar release profile with a significant increase in bioavailability compared to both pure piperine and Pip-SD.

\section{Polymeric nanocarriers}

The greatest advantage of polymeric nanocarriers (PNCs) is their ability to be synthesized for the specific purposes and functionalities required to meet the drug's needs in controlled temporal release, as well as for targeted therapeutic applications by tailoring its properties, such as size, shape, stability, porosity, surface charge, surface chemistry, and mechanical strength. For this reason, PNCs have been the most widely used approach for piperine formulations in the past $10 \mathrm{y}$, playing a dominant role in piperine delivery, especially for cancer therapy in various forms of nanocarrier (table 1). In vitro studies on triple-negative breast cancer (TNBC) cells, A549 lung cancer cells, HepG2 liver cancer cells, Hs683 human brain cancer cells, HeLa cervical cancer cells, and MCF-7 breast cancer cells have shown that PNCs enhance piperine cytotoxicity, due to increased accumulation on cancer cells, higher AUC, and extended drug circulation time, along with decreased nonspecific toxicity on normal cells compared to pure piperine (table 1). Piperine/Pluronic F127 nanomicelles even showed the lowest IC50 on the Hs683 human brain cancer cells line in the study and showed a comparable result to Erlotinib as standard [57].

When designing PNCs formulations, not only the chemical compositions and backbones of the polymers matter. Polymer architectures also significantly affect the drug carrier's properties and determine its effectiveness in delivering the drug. Polymer architectures portray the shape and topology of polymers, categorised as linear, graft, branched, cross-linked, block, starshaped, and dendron/dendrimer topology [58]. Cross-linked polymer architecture has been utilised in piperine polymer nanocarriers formulations, such as nanosponges, nanofibers mesh, and zein- $\kappa$-carrageenan nanoparticles. It has been reported that a high degree of crosslinking by diphenyl carbonate in piperine $/ \beta$ cyclodextrin nanosponges resulted in the increased surface area available for drug inclusion, thus enhancing drug loading efficiency [59]. On electrospun gelatin-based piperine nanofiber mesh formulations, layer-by-layer sequential cross-linking, achieved by exposure to saturated glutaraldehyde vapour for 6-8 $\mathrm{min}$ to overcome gelatin's poor structural consistency in water, yielded prolonged-controlled release with minimum initial burst close to zero-order release profile [60-62]. Another study revealed $\kappa$ carrageenan hydrogel shells, formed by interfacial cross-linking using $\mathrm{K}^{+}$around a zein core, demonstrated cross-linker concentration-dependent particle size and drug release rate [63]. Furthermore, increased $\mathrm{K}^{+}$concentration has been reported to yield extension of shelf-life and improved storage stability [63].

\section{Inorganic nanoparticles}

Organic nanoparticles have been developed successfully from polymers and lipids. Nevertheless, some of their inherent problems include low chemical stability, proneness to microbial contamination, and the negative effects of organic solvents used in the preparation [64]. Thus, inorganic nanoparticles that are less toxic, non-immunogenic, and highly stable compared to organic materials have been developed [64]. Hydroxyapatite is the main inorganic component of teeth and bones; thus, it has good biocompatibility compared to other inorganic materials [65]. Piperine-loaded hydroxyapatite nanoparticles, modified with phosphonate, coated with gum arabic, and conjugated to folic acid for targeted delivery systems showed a higher anticancer effect with full inhibition on monolayer HCT116 colon cancer cells and $\sim 60 \%$ inhibition on spheroids compared to pure piperine, along with lower cytotoxicity against normal WI-38 fibroblast cells, indicating high selectivity due to conjugation to folic acid as targeting ligand through folate receptors [65]. A long-term release effect is necessary for cancer therapy; this formulation's prolonged release profile extended to $>90 \mathrm{~h}$, much longer than other organic delivery systems [65].

\section{Hybrid nanoparticles (Microsphere-quantum dots)}

A recent development in piperine formulation is the synthesis of nanoparticles that combine microspheres and quantum dots [66]. Microspheres based on the polymer matrix hyaluronic acid (HA)/poly (lactic-co-glycolic acid) (PLGA) coated with copper oxide quantum dots (CuQDs), as piperine delivery targeted to the brain, showed a more controlled sustained release behaviour and increased antiepileptic activity, with lower toxicity than piperine in HA/PLGA microspheres and pure piperine [66]. In targeted drug delivery systems for brain disorders, the particle size of the nanocarriers plays a significant role. CuQDs were 5 to $10 \mathrm{~nm}$ in size, thus facilitating effective circulation within the capillaries and an easier passage through the blood-brain fields more easily [66].

\section{Limitations of developed formulations and future challenges}

In this last decade, various formulation strategies have been developed in order to overcome piperine's problems. However, among these formulations, thermodynamic stability is still a big issue, as piperine's metastable or amorphous state formation contributes to solubility and dissolution rate enhancement, leading to uncontrolled recrystallisation during storage. Metastable polymorphs tend to change to a more thermodynamically stable form in a relatively short time, hence close monitoring of polymorphic transformations is required during their formulation, manufacture and storage [67]. In addition, polymorphs are often clinical failures once they hit the market, due to their transformation into undesirable forms that have lower solubility or are even clinically harmful [12]. Amorphous recrystallisation will bring back piperine's natural poor solubility and make the efforts made to 
manage it fruitless. Thus, more studies are required of formulations' crystallisation behaviours, such as nucleation induction time, supersaturation tests as performed by [53], and shelf stability (the above-discussed studies have not done much to predict recrystallisation in storage). Solubility enhancement has been demonstrated with solubilizers such as cyclodextrins and surfactants, but studies have reported that these solubilisation mechanisms may forfeit intestinal absorption and lower apparent permeability due to reduced free drug availability for absorption $[68,69]$. Therefore, further studies on formulations' effect on intestinal permeability are necessary.

Table 1: Strategies to improve solubility and bioavailability of piperine

\begin{tabular}{|c|c|c|c|c|}
\hline Types and components & Techniques & Models/Methods used on studies & Result of studies & Ref \\
\hline \multicolumn{5}{|c|}{ Derivatives Analogue Synthesis } \\
\hline Vicinal difluoronation on & Stepwise & Photostability study by sunlight exposure; & $\uparrow$ Solubility and UV stability & \multirow[t]{2}{*}{ [11] } \\
\hline $\mathrm{C}=\mathrm{C}$ & fluorination & $\begin{array}{l}\text { solubility and bioactivity (AChE and BACE-1 } \\
\text { inhibitor) studies }\end{array}$ & $\downarrow$ IC50 as AChE inhibitor & \\
\hline \multicolumn{5}{|l|}{ Crystal Engineering } \\
\hline Polymorphism & $\begin{array}{l}\text { Polymer-induced } \\
\text { heteronucleation }\end{array}$ & $\begin{array}{l}\text { In situ dissolution rate study by monitoring } \\
\text { optical absorbance }\end{array}$ & $\begin{array}{l}\downarrow \text { Thermodynamic stability } \\
\uparrow \text { Intrinsic dissolution rate } 1.6 \text { - } \\
\text { fold }\end{array}$ & [13] \\
\hline $\begin{array}{l}\text { Salt formation PIP- } \\
\text { saccharin }\end{array}$ & Solvent evaporation & In vitro dissolution study by paddle method & $\uparrow$ Dissolution rate 1.8 -fold. & [14] \\
\hline Cocrystal PIP-succinic acid & $\begin{array}{l}\text { Solvent evaporation } \\
\text { dan slurry }\end{array}$ & $\begin{array}{l}\text { Solubility and in vitro dissolution study by } \\
\text { paddle method; stability study by PXRD (one } \\
\text { week) }\end{array}$ & $\begin{array}{l}\uparrow \text { Aquaeous solubility } 4 \text {-fold. } \\
\uparrow \text { Dissolution rate } 2.2 \text {-fold. } \\
\text { Good stability }\end{array}$ & {$[17]$} \\
\hline \multicolumn{5}{|l|}{ Emulsions dan SEDDS } \\
\hline SNEDDS & \multirow[t]{4}{*}{ Self-emulsification } & \multirow{4}{*}{$\begin{array}{l}\text { In vitro release study by paddle method; in vivo } \\
\text { oral absorption and pharmacokinetics studies } \\
\text { on Sprague-Dawley rats; in situ intestinal } \\
\text { absorption study by SPIP }\end{array}$} & $\uparrow$ Drug release 5.9-fold. & \multirow[t]{4}{*}{ [18] } \\
\hline PIP $2.5 \% \mathrm{w} / \mathrm{w}$, ethyl & & & $\uparrow$ Cmax 5-fold. & \\
\hline oleate: tween 80:transcutol & & & $\uparrow$ AUC 5.2-fold & \\
\hline $\mathrm{P}$ & & & Relative bioavailability $625,7 \%$ & \\
\hline SMEDDS & \multirow{4}{*}{$\begin{array}{l}\text { Self-emulsification, } \\
\text { spray-drying }\end{array}$} & \multirow{4}{*}{$\begin{array}{l}\text { Crystalline state study by PXRD; in vitro } \\
\text { anticancer study on KB cell lines by MTT assay; } \\
\text { in vitro release study by paddle; ex vivo } \\
\text { permeation study on male Wistar rats intestine; } \\
\text { stability studies by measurement of PS, PDI, \% } \\
\text { drug content after } 3 \text { mo }\end{array}$} & S-SMDDS>L-SMDDS>pure pip & \multirow[t]{4}{*}{ [19] } \\
\hline Miglyol 812, Cremophor & & & Amorphous fomation & \\
\hline EL/PEG-600 and & & & $\uparrow$ Cytotoxicity in KB cells $(\sim 1.5-$ & \\
\hline $\begin{array}{l}\text { Aerosil } 200 \text { (S-SMEDDS } \\
\text { carrier) }\end{array}$ & & & $\begin{array}{l}\text { fold), } \uparrow \text { Drug release } 2 \text {-fold, } \\
\text { intestinal permeability } 1.9 \text {-fold } \\
\text { Good stability }\end{array}$ & \\
\hline Microemulsion & \multirow[t]{5}{*}{ Water titration } & \multirow{5}{*}{$\begin{array}{l}\text { In vitro release study by dialysis bag method; } \\
\text { stability studies by measurement of PS, PDI, ZP, } \\
\% \text { transmittance after } 6 \text { mo; in vivo studies on } \\
\text { Alzheimer's male Wistar rats; nanotoxicological } \\
\text { studies by clinical observations and gross organ } \\
\text { examinations }\end{array}$} & Sustained release & \multirow[t]{5}{*}{ [20] } \\
\hline Capryol 90:Tween & & & $\uparrow$ Bioactivities (cognitive & \\
\hline 80/Cremophor RH & & & functions, brain neural apoptosis & \\
\hline 40:Transcutol HP & & & and inflammation suppression) & \\
\hline & & & Potential nephrotoxicity & \\
\hline \multicolumn{5}{|c|}{ Solid Lipid Nanoparticles and Nanostructured Lipid Carriers } \\
\hline \multirow{3}{*}{$\begin{array}{l}\text { PIP/GMS/Epikuron } 200 \\
\text { with polysorbate- } 80 \\
\text { coating }\end{array}$} & \multirow[t]{3}{*}{$\begin{array}{l}\text { Emulsification- } \\
\text { solvent diffusion }\end{array}$} & \multirow{3}{*}{$\begin{array}{l}\text { Stability studies by PS, ZP, EE measurement ( } 3 \\
\text { mo); in vivo bioactivity studies on albino Wistar } \\
\text { rats for Alzheimer's disease }\end{array}$} & $\begin{array}{l}\text { Significant changes on PS, ZP, EE } \\
(68.2 \rightarrow 47.5 \%)\end{array}$ & \multirow[t]{3}{*}{ [25] } \\
\hline & & & Amorphous state presence & \\
\hline & & & $\uparrow$ AUC on brain release 2.3 -fold & \\
\hline \multirow[t]{3}{*}{$\begin{array}{l}\text { PIP/Compritol® } 888 \\
\text { AT0/Squalene }\end{array}$} & $\begin{array}{l}\text { Solvent } \\
\text { evaporation, high }\end{array}$ & $\begin{array}{l}\text { In vitro drug release study; crystalline state } \\
\text { study by XRD and DSC; safety profile study by }\end{array}$ & $\begin{array}{l}\text { Drug released } 38 \% \text { within } 12 \mathrm{~h} \text {, } \\
\text { EE } 91.8 \%\end{array}$ & [27] \\
\hline & shear & haemolysis assay & Amorphous fomation & \\
\hline & $\begin{array}{l}\text { homogenization, } \\
\text { sonication }\end{array}$ & & No haemolysis in blood sample & \\
\hline Phospolipid Complexation & & & & \\
\hline PIP: HSPC & $\begin{array}{l}\text { Antisolvent } \\
\text { precipitation }\end{array}$ & $\begin{array}{l}\text { Crystallline state study by PXRD; in vitro release } \\
\text { studies by dialysis bag method; in vivo }\end{array}$ & $\begin{array}{l}\text { Amorphous formation, sustained } \\
\text { release, CE } 91.64 \%\end{array}$ & [30] \\
\hline & & $\begin{array}{l}\text { hepatoprotective activity and pharmacokinetics } \\
\text { studies on male Wistar rats; accelerated } \\
\text { stability studies ( } 3 \mathrm{mo} \text { ) }\end{array}$ & $\begin{array}{l}\uparrow \text { Solubility } 29.5 \text {-fold, dissolution } \\
\text { efficiency, AUC (10.4-fold), and } \\
\text { hepatoprotective activity } \\
\text { Good stability }\end{array}$ & \\
\hline Liposomes & & & & \\
\hline Nanoliposomes & Probe sonication & In vitro antioxidant potency study by DPPH & Sustained-delayed release & [34] \\
\hline Piperine $2 \%$ and soya PPC: & & radical scavenging activity; in vitro release & (commenced after $2 \mathrm{~h}$ ) & \\
\hline tween 80 & & $\begin{array}{l}\text { kinetic study by dialysis tube diffusion; storage } \\
\text { stability study ( } 3 \mathrm{mo})\end{array}$ & $\uparrow$ Stability & \\
\hline Pip: DPPC & $\begin{array}{l}\text { Modified reverse- } \\
\text { phase evaporation }\end{array}$ & $\begin{array}{l}\text { Stability studies (temporal, temperature, } \\
\text { membrane release by incubation) }\end{array}$ & $\uparrow$ Stability & [35] \\
\hline Cubosomes & & & & \\
\hline GMO/Tween & Self-assembly & In vitro release study by dialysis bag method; in & Sustained release & [38] \\
\hline 80/Poloxamer 407 & & $\begin{array}{l}\text { vivo bioactivity and toxicological studies on } \\
\text { male Wistar rats for Alzheimer's disease }\end{array}$ & $\uparrow$ Bioactivities & \\
\hline Inclusion Complexes & & & & \\
\hline TIC PIP/HP- $\beta-C D / P O L O$ & Freeze drying & Phase solubility and saturation solubility & $\uparrow$ Solubility 13 -fold, dissolution & [43] \\
\hline $0,5 \%$ & & studies; in vitro dissolution study by paddle & efficiency 2.8 -fold & \\
\hline & & $\begin{array}{l}\text { method; in vivo antiinflammatory study on } \\
\text { carrageenan-induced Wistar albino rats }\end{array}$ & $\begin{array}{l}\uparrow \text { Antiinflammatory, } 2 \text {-fold and } \\
\text { comparable to indomethacine) }\end{array}$ & \\
\hline
\end{tabular}




\begin{tabular}{|c|}
\hline $\mathrm{PIP} / \mathrm{EN}-\beta-\mathrm{CD}$ \\
\hline $\mathrm{PIP} / \alpha$-CDs $(\alpha, \beta, \gamma)$ \\
\hline TIC (HP $\beta$ CD and TPGS) \\
\hline
\end{tabular}

$\mathrm{PIP} / \beta$-CD

TIC ( $\beta$ CD and HPMC)

PIP/Cucurbiturils
PIP/ $\kappa$-carraageenan
Solid Dispersions
PIP/HPMCAS and
PIP/Eudragit L100-55

PIP/Soluplus ${ }^{\circledR}$

PIP/PVP
PIP/PEG
PIP/Sorbitol
FDT PIP:
PVPK25:phospolipid with
HPMC-K100

\section{Polymeric Nanocarriers}

Nanosuspensions $P$.

nigrum extract and HPMC

PIP/Pluronic F127

Nanomicelles with

Trimethyl-chitosan coating

PIP/Soluplus ${ }^{\circledR} /$ TPGS

Nanomicelles

\section{PIP/Gum resin}

Nanocapsules

PIP/Starch Nanoparticles

PIP/Aptamer/PEG/PLGA

Nanoparticles

Human Serum Albumin Nanoparticles

Core-shell

PIP-CoQ10/Zein- $\kappa$ -

Carraageenan

Nanoparticles

Multilayer PIP-

CoQ10/Zein-Pectin-

Chitosan Nanoparticles

Co-evaporation

Cogrinding (ground mixture)

Solvent evaporation and microwave irradiation (comparative)

Freeze drying

Solvent evaporation and microwave irradiation

Not stated Ground mixture

Solvent evaporation

Hot melt extrusion

Solvent method

Solvent (SD); extrusionspheronization (pellet); wet granulation (FDT)

Antisolvent precipitation

Nanoprecipitationliophilization

Thin-film hydration

Emulsion diffusion

In situ

nanoprecipitation Single emulsification, solvent evaporation Self-assembly, desolvation (comparative)

Antisolvent precipitation, stepwise electrostatic deposition Antisolvent precipitation, stepwise
Crystalline state study by XRD; in vitro

dissolution study by paddle type

Examination of crystalline state by PXRD; in vitro dissolution study by paddle method

Phase solubility and saturation solubility study; in vitro dissolution study by paddle method; in vitro antioxidant and antimicrobial assay

In vitro bioaccessibility, pungency, antioxidant capacity by simulated gastrointestinal digestion and colonic fermentation

Crystalline state studies by SEM and XRD; phase solubility and saturation solubility studies; in vitro dissolution study by paddle method; in vitro antioxidant and antimicrobial assay

Molecular interaction and stability studies In vivo studies on Wistar rats

Crystallization behavior studies; in vitro dissolution study under non-sink condition; in situ SPIP studies on male albino SpragueDawley rats

In vitro release study by paddle method; ex vivo permeablity study by non-everted intestinal sacs of male Spargue-Dawley rats Crystalline state studies by SEM and HR-XRD; in vitro dissolution profile study by paddle method

Crystalline state studies by SEM and XRD; in vitro dissolution study by rotary basket method. in vivo pharmacokinetics study on male beagle dogs; accelerated stability study (4 w)

In vtiro dissolution study by paddle method, in vivo pharmacokinetics study on male Wistar albino rats

In vitro release study; in vitro cytotoxicity studies on human brain cancer cells Hs683

In vitro release study by dialysis method; in vitro cytotoxicity studies by MTT assay and intracellular uptake of micelles on A549 lung cancer cells and $\mathrm{HepG}_{2}$ liver cancer cells; in vivo pharmacokinetics study on male Sprague-

Dawley rats

In vitro release study by dialysis bag method; in vitro evaluation of growth inhibition efficacy against T. evansi

In vitro release study by sonication

In vitro studies on MCF-7 cells

In vitro release by dialysis bag; in vitro cytotoxicity studies on MCF-7 cells by MTT assay

Stability studies (physical, thermal, 4-weeks storage, and photostability); crystalline state study by XRD; in vitro gastrointestinal digestion

Stability studies (physical, thermal, storage, and photostability); crystalline state study by XRD; simulated digestion evaluation

$\begin{array}{ll}\text { Amorphous fomation } & {[45]} \\ \uparrow \text { Dissolution 2.5-fold } & \\ \uparrow \text { Solubility 17.4-fold } & {[46,4} \\ \text { Amorphous fomation } & 7] \\ \text { MI>SE, amorphous formation } & {[42]}\end{array}$

$\uparrow$ Solubility 52.7-fold, dissolution 5.5-fold

$\uparrow$ Bioactivities (Antioxidant and antimicroba)

$\uparrow$ Bioaccessibility, intestine

permeability, antioxidant

capacity

Not effective in masking

pungency

MI>SE, Ks 464 M-1 CE 6.6

Amorphous formation, $\uparrow$

solubility 52.7-fold, $\uparrow$ dissolution

4.4-fold

$\uparrow$ Bioactivities

$\uparrow$ Stability

$\uparrow$ Cmax 2.8-fold, $\uparrow$ anti-

inflammatory activities

$\uparrow$ Recrystallization inhibition

$\uparrow$ Solubility, drug release,

permeability

Amorphous fomation, $\uparrow$ Solubility

160-fold, $\uparrow$ absorption 122-fold

Amorphous fomation, $\uparrow$

Dissolution (20-fold by PVP, 17 fold by PEG, 16-fold by sorbitol) Amorphous fomation, $\uparrow$ Solubility 4.5-fold (SD), sustained release $\uparrow \mathrm{t} 1 / 2$ 1.5-fold, MRT 1.4-fold, Cmax 2-fold, AUC 2,7-fold, relative bioavailability $267,7 \%$ Relatively hygroscopic with PIP content reduction $3.91 \%$

$\uparrow$ Dissolution 3.65-fold, Cmax

1.73-fold, bioavailability 2.7-fold, and MRT

Sustained release, $\uparrow$ Cytotoxicity with decreased IC50

Sustained-release, EE 90.9\%, DLC 4.67\%, $\uparrow$ AUC 2.56-fold and MRT 1.2 -fold

$\uparrow$ Antitumor efficacy

Sustained release, $\downarrow$ IC50 3-fold

$\uparrow$ Solubility, controlled release, DLC $4.74 \mathrm{mg} / \mathrm{mg}$

Sustained-release, $\uparrow$ Circulation time

Self-assembly>desolvation

EE 76.8\%, LC 8.92\%

$\uparrow$ Drug release, cytotoxicity, circulation time, accumulation on cancer cells

Controlled release, $\uparrow$ Stability (half-live 1.8-fold, retention rates on thermal treatment $200 \%$ and $131 \%$ on storage), amorphous formation

Amorphous formation, $\uparrow$ Stability 


\begin{tabular}{|c|c|c|c|c|}
\hline & $\begin{array}{l}\text { electrostatic } \\
\text { deposition }\end{array}$ & & & \\
\hline $\begin{array}{l}\text { PIP/Eudragit S100 } \\
\text { Nanoparticles }\end{array}$ & Nanoprecipitation & $\begin{array}{l}\text { In vitro release study by dialysis bag method; in } \\
\text { vivo pharmacokinetics characteristics studies } \\
\text { on Sprague-Dawley rats; in vivo antiepileptic } \\
\text { studies on zebrafish and male Kunming mice }\end{array}$ & $\begin{array}{l}\uparrow \text { Dissolution rate, cumulative } \\
\text { release } 3 \text {-fold, bioavailability } 2.7 \text { - } \\
\text { fold, brain concentration } 16 \text {-fold } \\
\uparrow \text { Antiepileptic effects }\end{array}$ & [91] \\
\hline $\begin{array}{l}\text { PIP/pCA-HT-chitosan } \\
\text { mucoadhessive } \\
\text { nanoparticles }\end{array}$ & $\begin{array}{l}\text { Electrospray } \\
\text { ionization }\end{array}$ & $\begin{array}{l}\text { In vitro release by dialysis bag (SIF pH } 1.2, \mathrm{SCF} \\
\mathrm{pH} 4.0, \mathrm{SIF} 6.4,100 \mathrm{rpm})\end{array}$ & Sustained release & [92] \\
\hline $\begin{array}{l}\text { PIP/HP-starch } \\
\text { nanoparticles }\end{array}$ & $\begin{array}{l}\text { In situ } \\
\text { nanoprecipitation }\end{array}$ & $\begin{array}{l}\text { In vitro release study in PBS }(\mathrm{pH} 1.2,7.4,8.6) \text { at } \\
37^{\circ} \mathrm{C}\end{array}$ & Controlled release & {$[93]$} \\
\hline $\begin{array}{l}\text { PIP/mPEG-PLGA } \\
\text { nanoparticles }\end{array}$ & Thin-film hydration & In vitro studies on TNBC cells by MTT assay & $\begin{array}{l}\uparrow \text { Selectivity towards non-cancer } \\
\text { cells }\end{array}$ & [94] \\
\hline $\begin{array}{l}\mathrm{PIP} / \text { poli( }(\varepsilon- \\
\text { caprolactone }) / \text { gelatin } \\
\text { nanofibrous patches }\end{array}$ & Electrospinning & $\begin{array}{l}\text { In vitro release kinetics study; in vitro study on } \\
\text { HeLa and MCF-7 cancer cells and non-cancerous } \\
\text { cells (NIH3T3 and human mesenchymal stem } \\
\text { cells) }\end{array}$ & $\begin{array}{l}\text { Sustained release } \\
\uparrow \text { Selectivity towards non-cancer } \\
\text { cells }\end{array}$ & {$[95]$} \\
\hline $\begin{array}{l}\text { PIP/Gelatin/GTA nanofiber } \\
\text { mesh }\end{array}$ & $\begin{array}{l}\text { Electrospinning } \\
\text { Sequential crosslink }\end{array}$ & $\begin{array}{l}\text { In vitro degradation and swelling study; thermal } \\
\text { stability studies; in vitro drug release study }\end{array}$ & $\begin{array}{l}\uparrow \text { Nanofiber structure integrity } \\
\uparrow \text { Stability (compared to one time } \\
\text { direct crosslinked fiber mesh) } \\
\text { Sustained release }\end{array}$ & {$[60]$} \\
\hline $\begin{array}{l}\text { PIP/Gelatin/GTA nanofiber } \\
\text { mesh }\end{array}$ & $\begin{array}{l}\text { Electrospinning, } \\
\text { multilayer- } \\
\text { sequential crosslink }\end{array}$ & $\begin{array}{l}\text { In vitro degradation study; thermal stability } \\
\text { studies; in vitro drug release study }\end{array}$ & $\begin{array}{l}\text { No significant changes compared } \\
\text { to nonmultilayer } \\
\text { PIP/gelatin/GTA nanofibers }\end{array}$ & $\begin{array}{l}{[61,6} \\
2]\end{array}$ \\
\hline $\begin{array}{l}\mathrm{PIP} / \beta-\mathrm{CD} / \mathrm{DPC} \\
\text { nanosponges }\end{array}$ & Solvent & $\begin{array}{l}\text { Crystalline state study by XRD; drug release } \\
\text { study was not studied }\end{array}$ & NS in para-crystalline structure & [96] \\
\hline $\begin{array}{l}\mathrm{PIP} / \beta-\mathrm{CD} / \mathrm{DPC} \\
\text { nanosponges }\end{array}$ & $\begin{array}{l}\text { Microwave-Assisted } \\
\text { Fusion }\end{array}$ & $\begin{array}{l}\text { Crystalline state study by PXRD; drug release } \\
\text { study was not studied }\end{array}$ & $\begin{array}{l}\text { NS in crystalline structure } \\
\text { Crosslinking increase NS } \\
\text { crystallinity and LE }\end{array}$ & {$[59]$} \\
\hline $\begin{array}{l}\text { Inorganic Nanoparticles } \\
\text { PIP/Hydroxyapatite- } \\
\text { phosphonate NPs } \\
\text { functionalized with gum } \\
\text { arabic/folic acid }\end{array}$ & Hydrothermal & $\begin{array}{l}\text { In vitro release studies by bottle method with } \\
\text { cellulose dialysis bag; in vitro study on HCT116, } \\
\text { Caco } 2 \text { colon cancer cells and MCF-7 breast } \\
\text { cancer cells }\end{array}$ & $\begin{array}{l}\uparrow \text { Release rate at pH } 5 \text { and } 6.8 \text {, } \\
\text { prolonged release at pH } 7.4 \\
\uparrow \text { Inhibitory effects toward cancer } \\
\text { cells (full inhibition on HCT } 116 \text { ) } \\
\downarrow \text { Toxicity on normal cells }\end{array}$ & {$[65]$} \\
\hline $\begin{array}{l}\text { Hybrid Nanoparticles } \\
\text { Hyaluronic } \\
\text { acid/PLGA+CuO Quantum } \\
\text { Dots PIP Microspheres }\end{array}$ & $\begin{array}{l}\text { Precipitation, } \\
\text { emulsification- } \\
\text { solvent evaporation }\end{array}$ & $\begin{array}{l}\text { Crystalline state study by XRD; in vitro release } \\
\text { study by biolysis bag protocol; MTT assay and in } \\
\text { vivo antiepileptic activity by kindling } \\
\text { procedures on male Wistar rats }\end{array}$ & $\begin{array}{l}\text { Controlled sustained release } \\
\downarrow \text { Toxicity, } \uparrow \text { Selectivity, } \uparrow \\
\text { Antiepileptic and anticonvulsant }\end{array}$ & {$[66]$} \\
\hline
\end{tabular}

Polymer-based formulations have limitations. Many polymer carriers are hygroscopic (as shown on piperine solid dispersions fast disintegrating tablets) and cause system plasticisation, increasing the mobility of the API molecules to crystallize [70]. In addition, drug formulations have high doses due to the final product's increased volume [71]. Piperine lipid-based formulations still need to be improved for long-term storage stability. A potential strategy that may possible to resolve the stability problem is pro-form formulations (proliposomes and procubosomes). Proliposomes and procubosomes are dry and free-flowing powders that could form liposomes and cubosomes by hydration with water, either through contact with physiological fluid or reconstitution right before administration, and thus can be stored for long time [72-74]. Proliposomes has proven able to improve drug compounds with poor solubility and bioavailability significantly in several studies [73-76]. However, there has been only one study on procubosome formulation to date [72]. Procubosome compressed into tablet form successfully improved the solubility of BCS class II drug clopidogrel and even obtained superior $\mathrm{C}_{\max }, \mathrm{T}_{\max }$, bioavailability, and antiplatelet activity, compared to commercial Plavix ${ }^{\circledR}$ as standard. Moreover, procubosome formulation has successfully retained the fresh tablet drug content (98.5\%) after storage for six months [72]. Therefore, this strategy could lead to an interesting future development of high stable lipid-based drug delivery systems that enhance piperine solubility and bioavailability, as well as those of other drug candidate compounds facing the same limitations.

Concerning to the number of uses of nano-sized drug delivery systems in piperine formulations, toxicity must be investigated carefully since the materials used in nanoformulation have different properties depending on size, resulting in increased tissue and organ uptake $[20,77]$. Previous studies have demonstrated the possible toxicity of nanosystems and nanosurfactants and their ability to interact differently with biological and cellular barriers [20, 78, 79]. Taking these studies into consideration, it is important to reassess safe concentrations of the nanomaterials and conduct more nanotoxicology studies. In addition, any modifications to nanoparticles as carriers have to be evaluated thoroughly, because immune system responses could reduce their half-life [80]. Study of formulations' UV stability is still lacking. This property is actually really important for consideration since UV can directly diminish piperine level through photoisomerisation. Derivatives and analogue synthesis derived from piperine studies with solubility and bioavailability enhancement as objectives are also still limited, despite the considerable number of piperine derivatisation studies, as well as studies that have used this approach to solve similar problems on BCS class II drug compounds. This approach also may lead to the finding of a soluble prodrug derived from piperineactually an older but time-tested strategy to overcome the solubility problem, and which can even be used as targeted drug delivery in the more novel application of this strategy [81-83].

\section{CONCLUSION}

Piperine has gained interest as a phytocompound that displays multiple great beneficial effects as a therapeutic agent. However, its poor solubility and bioavailability limit its biological effects in vivo and thus its clinical applications. In the last decade, various formulation strategies with different methodological approaches have been performed, improving piperine's physicochemical, pharmacokinetic, and pharmacodynamics properties. An increase in bioactivity, particularly on brain diseases and cancers, has been demonstrated as the outcome of these approaches. These results encourage us to perform further stability and in vivo studies, 
continuing these efforts to optimise piperine's potential so it can be used for clinical applications in the future.

\section{ACKNOWLEDGEMENT}

The authors would like to acknowledge the funding support from Andalas University for Grant Research PGB contract number T/12/UN.16.17/PT.01.03/KO-PDU-KRP1GB/2020.

\section{AUTHORS CONTRIBUTIONS}

Design and conception of this study were led by Erizal Zaini. All authors contributed substantially in article drafting or critical revisions for important intellectual content and give final approval of the version to be published.

\section{CONFLICT OF INTERESTS}

The authors declare no conflict of interests.

\section{REFERENCES}

1. Tiwari A, Mahadik KR, Gabhe SY. Piperine: a comprehensive review of methods of isolation, purification, and biological properties. Med Drug Discovery 2020;7:1-18.

2. Stojanovic Radic Z, Pejcic M, Dimitrijevic M, Aleksic A, Anil Kumar NV, Salehi B, et al. Piperine-a major principle of black pepper: a review of its bioactivity and studies. Appl Sci 2019;9:1-29.

3. Gorgani L, Mohammadi M, Najafpour GD, Nikzad M. Piperinethe bioactive compound of black pepper: from isolation to medicinal formulations. Compr Rev Food Sci Food Saf 2017;16:124-40.

4. Quijia CR, Araujo VH, Chorilli M. Piperine: chemical, biological and nanotechnological applications. Acta Pharm 2021;71:185-213.

5. Haq IU, Imran M, Nadeem M, Tufail T, Gondal TA, Mubarak MS. Piperine: a review of its biological effects. Phytother Res 2020;1-21. https://doi.org/10.1002/ptr.6855

6. Rout J, Swain BC, Tripathy U. In silico investigation of spice molecules as potent inhibitor of SARS-CoV-2. J Biomol Struct Dyn 2020;1-15. https://doi.org/10.1080/07391102.2020.1819879

7. Kumar S, Kashyap P, Chowdhury S, Kumar S, Panwar A, Kumar A. Identification of phytochemicals as potential therapeutic agents that binds to Nsp15 protein target of coronavirus (SARS-CoV-2) that are capable of inhibiting virus replication. Phytomedicine 2020;85:1-10.

8. Ahmad I, Ahmed S, Anwar Z, Sheraz MA, Sikorski M. Photostability and photostabilization of drugs and drug products. Int J Photoenergy 2016;2016:1-19.

9. Kozukue N, Park MS, Choi SH, Lee SU, Ohnishi Kameyama M, Levin $\mathrm{CE}$, et al. Kinetics of light-induced cis-trans isomerization of four piperines and their levels in ground black peppers as determined by HPLC and LC/MS. J Agric Food Chem 2007;55:7131-9.

10. Hashimoto K, Yaoi T, Koshiba H, Yoshida T, Maoka T, Fujiwara $\mathrm{Y}$, et al. Photochemical isomerization of piperine, a pungent constituent in pepper. Food Sci Technol Int Tokyo 1996;2:24-9.

11. Lizarme Salas Y, Ariawan AD, Ratnayake R, Luesch H, Finch A, Hunter L. Vicinal difluorination as a $\mathrm{C}=\mathrm{C}$ surrogate: an analog of piperine with enhanced solubility, photostability, and acetylcholinesterase inhibitory activity. Beilstein J Org Chem 2020;16:2663-70.

12. Censi R, Di Martino P. Polymorph impact on the bioavailability and stability of poorly soluble drugs. Molecules 2015;20:18759-76.

13. Pfund LY, Chamberlin BL, Matzger AJ. The bioenhancer piperine is at least trimorphic. Cryst Growth Des 2015;15:2047-51.

14. Zaini E, Riska D, Oktavia MD, Ismed F, Fitriani L. Improving dissolution rate of piperine by multicomponent crystal formation with saccharin. Res J Pharm Technol 2019;13:1926-30.

15. Childs SL, Stahly GP, Park A. The salt-cocrystal continuum: the influence of crystal structure on ionization state. Mol Pharm 2007;4:323-38.

16. Cruz Cabeza AJ. Acid-base crystalline complexes and the pKa rule. Cryst Eng Comm 2012;14:6362-5.

17. Zaini E, Afriyani, Fitriani L, Ismed F, Horikawa A, Uekusa H. Improved solubility and dissolution rates in novel multicomponent crystals of piperine with succinic acid. Sci Pharm 2020;88:1-12.

18. Shao B, Cui C, Ji H, Tang J, Wang Z, Liu H, et al. Enhanced oral bioavailability of piperine by self-emulsifying drug delivery systems: in vitro, in vivo and in situ intestinal permeability studies. Drug Delivery 2015;22:740-7.

19. Patil SC, Tagalpallewar AA, Kokare CR. Natural antiproliferative agent loaded self-microemulsifying nanoparticles for potential therapy in oral squamous carcinoma. J Pharm Investig 2019;49:527-41.

20. Etman SM, Elnaggar YSR, Abdelmonsif DA, Abdallah OY. Oral BrainTargeted Microemulsion for Enhanced Piperine Delivery in Alzheimer's Disease Therapy: In vitro Appraisal, In vivo Activity, and Nanotoxicity. AAPS PharmSciTech 2018;19:3698-711.

21. Rao Z, Si L, Guan Y, Pan H, Qiu J, Li G. Inhibitive effect of cremophor RH40 or tween 80-based self-microemulsiflying drug delivery system on cytochrome P450 3A enzymes in murine hepatocytes. J Huazhong Univ Sci Technol Med Sci 2010;30:562-8.

22. Prabhakar K, Afzal SM, Surender G, Kishan V. Tween 80 containing lipid nanoemulsions for delivery of indinavir to brain. Acta Pharm Sin B 2013;3:345-53.

23. Yadav N, Khatak S, Singh Sara UV. Solid lipid nanoparticles-a review. Int J Appl Pharm 2013;5:8-18.

24. Ghasemiyeh P, Mohammadi Samani S. Solid lipid nanoparticles and nanostructured lipid carriers as novel drug delivery systems: applications, advantages and disadvantages. Res Pharm Sci 2018;13:288-303.

25. Yusuf M, Khan M, Khan RA, Ahmed B. Preparation, characterization, in vivo and biochemical evaluation of brain targeted piperine solid lipid nanoparticles in an experimentally induced Alzheimer's disease model. J Drug Target 2013;21:300-11.

26. Nobari Azar FA, Pezeshki A, Ghanbarzadeh B, Hamishehkar H, Mohammadi M. Nanostructured lipid carriers: promising delivery systems for encapsulation of food ingredients. J Agric Food Res 2020;2:1-8.

27. Chaudhari VS, Murty US, Banerjee S. Nanostructured lipid carriers as a strategy for encapsulation of active plant constituents: Formulation and in vitro physicochemical characterizations. Chem Phys Lipids 2021;235:105037.

28. Kalepu S, Manthina M, Padavala V. Oral lipid-based drug delivery systems-an overview. Acta Pharm Sin B 2013;3:361-72.

29. Kuche K, Bhargavi N, Dora CP, Jain S. Drug-phospholipid complex-a go through strategy for enhanced oral bioavailability. AAPS PharmSciTech 2019;20:1-13.

30. Biswas S, Mukherjee PK, Kar A, Bannerjee S, Charoensub R, Duangyod T. Optimized piperine-phospholipid complex with enhanced bioavailability and hepatoprotective activity. Pharm Dev Technol 2021;26:69-80.

31. Kalepu S, Nekkanti V. Insoluble drug delivery strategies: review of recent advances and business prospects. Acta Pharm Sin B 2015;5:442-53.

32. Daeihamed M, Dadashzadeh S, Haeri A, Akhlaghi MF. Potential of liposomes for enhancement of oral drug absorption. Curr Drug Delivery 2017;14:289-303.

33. Lee MK. Liposomes for enhanced bioavailability of waterinsoluble drugs: in vivo evidence and recent approaches. Pharmaceutics 2020;12:264-94.

34. Dutta S, Bhattacharjee P. Nanoliposomal encapsulates of piperine-rich black pepper extract obtained by enzymeassisted supercritical carbon dioxide extraction. J Food Eng 2017;201:49-56.

35. Pentak D. In vitro spectroscopic study of piperine-encapsulated nanosize liposomes. Eur Biophys J 2016;45:175-86.

36. Karami Z, Hamidi M. Cubosomes: remarkable drug delivery potential. Drug Discovery Today 2016;21:789-801.

37. Barriga HMG, Holme MN, Stevens MM. Cubosomes: the next generation of smart lipid nanoparticles? Angew Chem Int Ed 2019;58:2958-78.

38. Elnaggar YSR, Etman SM, Abdelmonsif DA, Abdallah OY. Novel piperine-loaded Tween-integrated monoolein cubosomes as brain-targeted oral nanomedicine in Alzheimer's disease: pharmaceutical, biological, and toxicological studies. Int J Nanomed 2015;10:5459-73.

39. Octavia MD, Halim A, Zaini E. Preparation of simvastatin- $\beta$ cyclodextrin inclusion complexes using the co-evaporation technique. J Chem Pharm Res 2015;7:740-7.

40. Parmar V, Patel G, Abu Thabit NY. Responsive cyclodextrins as polymeric carriers for drug delivery applications. In: Makhlouf 
ASH, Abu-Thabit NY. editors. Stimuli-responsive polymeric nanocarriers for drug delivery applications: Vol. 1. Types and triggers cambridge: Woodhead Publishing Limited; 2018. p. 555-80.

41. Alshehri S, Imam SS, Hussain A, Altamimi MA. Formulation of piperine ternary inclusion complex using $\beta \mathrm{CD}$ and HPMC: physicochemical characterization, molecular docking, and antimicrobial testing. Processes 2020;8:1450-65.

42. Imam SS, Alshehri S, Alzahrani TA, Hussain A, Altamimi MA. Formulation and evaluation of supramolecular food-grade piperine HP $\beta$ CD and TPGS complex: dissolution, physicochemical characterization, molecular docking, in vitro antioxidant activity, and antimicrobial assessment. Molecules 2020;25:4716-37.

43. Kulkarni AS, Dias RJ, Ghorpade VS, Mali KK. Freeze-dried multicomponent inclusion complexes of piperine with cyclodextrin and hydrophilic polymers: Physicochemical characterization and in vivo anti-inflammatory activity. Res J Pharm Technol 2020;13:4916.

44. Ezawa T, Inoue Y, Murata I, Takao K, Sugita Y, Kanamoto I. Evaluation of the molecular state of piperine in cyclodextrin complexes by near-infrared spectroscopy and solid-state fluorescence measurements. Int J Med Chem 2019;2019:1-14.

45. Liu K, Liu H, Li Z, Li W, Li L. In vitro dissolution study on inclusion complex of piperine with ethylenediamine- $\beta$ cyclodextrin. J Incl Phenom Macrocycl Chem 2020;96:233-43.

46. Ezawa T, Inoue Y, Tunvichien S, Suzuki R, Kanamoto I. Changes in the physicochemical properties of piperine/ $\beta$-cyclodextrin due to the formation of inclusion complexes. Int J Med Chem 2016;2016:1-9.

47. Ezawa T, Inoue Y, Murata I, Takao K, Sugita Y, Kanamoto I. Characterization of the dissolution behavior of piperine/cyclodextrins inclusion complexes. AAPS PharmSciTech 2018;19:923-33.

48. Quilaqueo M, Millao S, Luzardo Ocampo I, Campos Vega R, Acevedo $\mathrm{F}$, Shene $\mathrm{C}$, et al. Inclusion of piperine in $\beta$ cyclodextrin complexes improves their bioaccessibility and in vitro antioxidant capacity. Food Hydrocoll 2019;91:143-52.

49. Tong WQ (Tony), Wen H. Application of complexation in drug development for insoluble compounds. In: Liu R. editor. Waterinsoluble drug formulation. Third edit. Boca Raton: CRC Press; 2018. p. 150-70.

50. Mohanty B, Suvitha A, Venkataramanan NS. Piperine encapsulation within cucurbit[n]uril $(n=6,7)$ : a combined experimental and density functional study. Chem Select 2018;3:1933-41.

51. Simanjuntak N, Levita J, Subarnas A. Inclusion of biopiperine in the kappa-carrageenan complex might improve its bioaccessibility and in vivo anti-inflammatory activity in edema-induced wistar rats. J Appl Pharm Sci 2020;10:39-43.

52. Fitriani L, Afriyanti I, Afriyani, Ismed F, Zaini E. Solid dispersion of usnic acid-HPMC 2910 prepared by spray drying and freeze drying techniques. Orient J Chem 2018;34:2083-8.

53. Deng Y, Liang Q, Wang Y, Zhang X, Yan C, He Y. The inhibiting role of hydroxypropylmethylcellulose acetate succinate on piperine crystallization to enhance its dissolution from its amorphous solid dispersion and permeability. RSC Adv 2019;9:39523-31.

54. Ashour EA, Majumdar S, Alsheteli A, Alshehri S, Alsulays B, Feng $\mathrm{X}$, et al. Hot melt extrusion as an approach to improve solubility, permeability and oral absorption of a psychoactive natural product, piperine. J Pharm Pharmacol 2016;68:989-98.

55. Thenmozhi K, Yoo YJ. Enhanced solubility of piperine using hydrophilic carrier-based potent solid dispersion systems. Drug Dev Ind Pharm 2017;43:1501-9.

56. Zhu Y, Yu J, Zhou G, Gu Z, Adu-Frimpong M, Deng W, et al. Piperine fast disintegrating tablets comprising sustainedrelease matrix pellets with enhanced bioavailability: formulation, in vitro and in vivo evaluation. Pharm Dev Technol 2020;25:617-24.

57. Sedeky AS, Khalil IA, Hefnawy A, El-Sherbiny IM. Development of core-shell nanocarrier system for augmenting piperine cytotoxic activity against human brain cancer cell line. Eur J Pharm Sci 2018;118:103-12.
58. Qiu LY, Bae YH. Polymer architecture and drug delivery. Pharm Res 2006;23:1-30.

59. Guineo Alvarado J, Quilaqueo M, Hermosilla J, González S, Medina C, Rolleri A, et al. Degree of crosslinking in $\beta$ cyclodextrin-based nanosponges and their effect on piperine encapsulation. Food Chem 2021;340:1-7.

60. Laha A, Sharma CS, Majumdar S. Electrospun gelatin nanofibers as drug carrier: effect of crosslinking on sustained release. Mater Today Proc 2016;3:3484-91.

61. Laha A, Majumdar S, Sharma CS. Controlled drug release formulation by sequential crosslinking of multilayered electrospun gelatin nanofiber mat. MRS Adv 2016;1:2107-13.

62. Laha A, Sharma CS, Majumdar S. Sustained drug release from multi-layered sequentially crosslinked electrospun gelatin nanofiber mesh. Mater Sci Eng C 2017;76:782-6.

63. Chen S, Zhang Y, Qing J, Han Y, McClements DJ, Gao Y. Core-shell nanoparticles for co-encapsulation of coenzyme Q10 and piperine: surface engineering of hydrogel shell around protein core. Food Hydrocoll 2020;103:1-11.

64. Paul W, Sharma CP. Inorganic nanoparticles for targeted drug delivery. In: Sharma CP. editor. Biointegration of medical implant materials: science and design cambridge: Woodhead Publishing Limited; 2010. p. 204-35.

65. AbouAitah K, Stefanek A, Higazy IM, Janczewska M, Swiderska Sroda A, Chodara A, et al. Effective targeting of colon cancer cells with piperine natural anticancer prodrug using functionalized clusters of hydroxyapatite nanoparticles. Pharmaceutics 2020;12:1-28.

66. Zhu D, Zhang W Guang, Nie X Dan, Ding S Wen, Zhang D Tai, Yang L. Rational design of ultra-small photoluminescent copper nano-dots loaded PLGA micro-vessels for targeted co-delivery of natural piperine molecules for the treatment for epilepsy. J Photochem Photobiol B Biol 2020;205:1-8.

67. Murdande SB, Pikal MJ, Shanker RM, Bogner RH. Aqueous solubility of crystalline and amorphous drugs: challenges in measurement. Pharm Dev Technol 2011;16:187-200.

68. Miller JM, Beig A, Carr RA, Spence JK, Dahan A. A win-win solution in oral delivery of lipophilic drugs: supersaturation via amorphous solid dispersions increases apparent solubility without sacrifice of intestinal membrane permeability. Mol Pharm 2012;9:2009-16.

69. Miller JM, Beig A, Krieg BJ, Carr RA, Borchardt TB, Amidon GE, et al. The solubility-permeability interplay: mechanistic modeling and predictive application of the impact of micellar solubilization on intestinal permeation. Mol Pharm 2011;8:1848-56.

70. Mehta M, Kothari K, Ragoonanan V, Suryanarayanan R. Effect of water on molecular mobility and physical stability of amorphous pharmaceuticals. Mol Pharm 2016;13:1339-46.

71. Shi Q, Moinuddin SM, Cai T. Advances in coamorphous drug delivery systems. Acta Pharm Sin B 2019;9:19-35.

72. El-Laithy HM, Badawi A, Abdelmalak NS, Elsayyad NME. Stabilizing excipients for engineered clopidogrel bisulfate procubosome derived in situ cubosomes for enhanced intestinal dissolution: stability and bioavailability considerations. Eur J Pharm Sci 2019;136:1-11.

73. Janga KY, Jukanti R, Velpula A, Sunkavalli S, Bandari S, Kandadi $\mathrm{P}$, et al. Bioavailability enhancement of zaleplon via proliposomes: role of surface charge. Eur J Pharm Biopharm 2012;80:347-57.

74. Nekkanti V, Venkatesan N, Betageri G. Proliposomes for oral delivery: progress and challenges. Curr Pharm Biotechnol 2015;16:303-12.

75. Rahamathulla M, HVG, Veerapu G, Hani U, Alhamhoom Y, Alqahtani A, et al. Characterization, optimization, in vitro and in vivo evaluation of simvastatin proliposomes, as drug delivery. AAPS PharmSciTech 2020;21:1-15.

76. Ren J, Fang Z, Jiang L, Du Q. Quercetin-containing self-assemble proliposome preparation and evaluation. J Liposome Res 2017;27:335-42.

77. Jong WH De, Paul JB. Drug delivery and nanoparticles: applications and hazards. Int J Nanomed 2008;3:133-49.

78. Nogueira DR, Carmen Moran M Del, Mitjans M, Perez L, Ramos D, De Lapuente J, et al. Lysine-based surfactants in nanovesicle 
formulations: the role of cationic charge position and hydrophobicity in in vitro cytotoxicity and intracellular delivery. Nanotoxicology 2014;8:404-21.

79. Zhang XQ, Xu X, Bertrand N, Pridgen E, Swami A, Farokhzad OC. Interactions of nanomaterials and biological systems: implications to personalized nanomedicine. Adv Drug Delivery Rev 2012;64:1363-84.

80. Watkins $\mathrm{R}, \mathrm{Wu} \mathrm{L}$, Zhang $\mathrm{C}$, Davis $\mathrm{RM}, \mathrm{Xu}$ B. Natural productbased nanomedicine: recent advances and issues. Int J Nanomed 2015;10:6055-74.

81. Dahan A, Zimmermann EM, Ben-Shabat S. Modern prodrug design for targeted oral drug delivery. Molecules 2014;19:16489-505.

82. Huttunen KM, Raunio H, Rautio J. Prodrugs-from serendipity to rational design. Pharmacol Rev 2011;63:750-71.

83. Stella VJ, Nti-Addae KW. Prodrug strategies to overcome poor water solubility. Adv Drug Deliv Rev 2007;59:677-94.

84. Zafar F, Jahan N, Khalil-Ur-Rahman, Bhatti HN. Increased oral bioavailability of piperine from an optimized piper nigrum nanosuspension. Planta Med 2019;85:249-57.

85. Ding Y, Wang C, Wang Y, Xu Y, Zhao J, Gao M, et al. Development and evaluation of novel drug delivery: Soluplus®/TPGS mixed micelles loaded with piperine in vitro and in vivo. Drug Dev Ind Pharm 2018;44:1409-16.

86. Rani R, Kumar S, Dilbaghi N, Kumar R. Nanotechnology enabled the enhancement of antitrypanosomal activity of piperine against trypanosoma evansi. Exp Parasitol 2020;219:1-8.

87. Chong WH, Chin SF, Pang SC, Kok KY. Synthesis and characterisation of piperine-loaded starch nanoparticles. J Phys Sci 2020;31:57-68.

88. Pachauri M, Gupta ED, Ghosh PC. Piperine loaded PEG-PLGA nanoparticles: Preparation, characterization and targeted delivery for adjuvant breast cancer chemotherapy. J Drug Delivery Sci Technol 2015;29:269-82.

89. Abolhassani H, Shojaosadati SA. A comparative and systematic approach to desolvation and self-assembly methods for synthesis of piperine-loaded human serum albumin nanoparticles. Colloids Surfaces B 2019;184:1-25.

90. Chen S, Zhang Y, Han Y, McClements DJ, Liao W, Mao L, et al. Fabrication of multilayer structural microparticles for coencapsulating coenzyme Q10 and piperine: effect of the encapsulation location and interface thickness. Food Hydrocoll 2020;109:1-44.

91. Ren T, Hu M, Cheng Y, Shek TL, Xiao M, Ho NJ, et al. Piperineloaded nanoparticles with enhanced dissolution and oral bioavailability for epilepsy control. Eur J Pharm Sci 2019;137:1-8.

92. Pengpong T, Sangvanich P, Sirilertmukul K, Muangsin N. Design, synthesis and in vitro evaluation of mucoadhesive $\mathrm{p}$ coumarate-thiolated-chitosan as a hydrophobic drug carrier. Eur J Pharm Biopharm 2014;86:487-97.

93. Salim AB, Chin SF, Pang SC. Hydroxypropyl starch nanoparticles as controlled release nanocarriers for piperine. J Nanostructures 2020;10:327-36.

94. Rad JG, Hoskin DW. Delivery of apoptosis-inducing piperine to triple-negative breast cancer cells via co-polymeric nanoparticles. Anticancer Res 2020;40:689-94.

95. Jain S, Meka SRK, Chatterjee K. Engineering a piperine eluting nanofibrous patch for cancer treatment. ACS Biomater Sci Eng 2016;2:1376-85.

96. Garrido B, González S, Hermosilla J, Millao S, Quilaqueo M, Guineo J, et al. Carbonate- $\beta$-cyclodextrin-based nanosponge as a nanoencapsulation system for piperine: physicochemical characterization. J Soil Sci Plant Nutr 2019;19:620-30. 